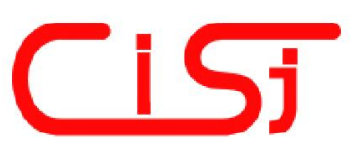

\title{
DESIGN OF THE FUZZY CONTROL SYSTEM FOR THE WASTE HEAT UTILIZATION PLANTS DRIVEN BY THE THERMOACOUSTIC ENGINE
}

\author{
Yuriy Kondratenko 1), Volodymyr Korobko ${ }^{2)}$, \\ Oleksiy Korobko ${ }^{2)}$, Oleksiy Moskovko ${ }^{2)}$
${ }^{1)}$ Petro Mohyla Black Sea State University, 10 68th Desantnykiv st., Mykolaiv, Ukraine, y_kondratenko@rambler.ru
${ }^{2)}$ Admiral Makarov National University of Shipbuilding, 9 Geroiv Stalingrada ave., Mykolaiv, Ukraine, volodymyr.korobko@nuos.edu.ua, oleksii.korobko@nuos.edu.ua, oleksiy.moskovko@nuos.edu.ua

\begin{abstract}
The paper addresses the synthesis of fuzzy controllers for computerized control system of the waste heat energy (WHE) utilization plants that operate with the thermoacoustic engine (TAE). Based on the analysis of existing systems, the authors present the main tasks of the synthesized control system, describe its structure and main components. Created system is then tested on the experimental thermoacoustic installation. Using the data obtained authors synthesize the mathematical model of thermoacoustic plant and describe the methodology of its control by the adjustments in resonator length of thermoacoustic device. Using the suggested approach authors design a number of conventional discrete and fuzzy controllers and provide the comparative analysis of quality indicators of the designed control systems transient responses. Copyright (C) Research Institute for Intelligent Computer Systems, 2014. All rights reserved.
\end{abstract}

Keywords: energy utilization, thermoacoustic plant, control system, fuzzy controllers

\section{INTRODUCTION}

The current state of society and industry leads to high energy consumption. High level of energy production causes the decrease in renewable mineral resources stocks and also the increase in global ecological problems, such as chemical pollution, thermal emissions and greenhouse gases. Therefore, the innovative energy efficiency technologies development and implementation is a primary task.

Today the thermal power plants (TPP), which operate through heat engines, provide most of energy. In simplified form energy balance of conditional TPP can be written as

$$
Q_{\text {fuel }}=Q_{h e}+Q_{w h}+Q_{\text {loses }} .
$$

Modern heat engines are able to convert only part of the fuel heat into mechanical energy $Q_{h e}$. The work of heat engine is accompanied by the emission of heat in the environment $Q_{w h}+Q_{\text {loses }}$. Part of this emission that can be reused by existing TPP is the waste heat energy resources $Q_{w h}$. The heat that is technologically impossible or economically impractical to use creates the thermal pollution $Q_{\text {loses }}$.

The part of energy converted by the engine $Q_{h e}$ shows the degree of heat engine technical and thermodynamic perfection. The value of $Q_{w h}$ depends on the structural effectiveness, coolant temperature, TPP's thermo-physical properties, and existing technologies. Thus, applying the new saving technologies to increase the value of $Q_{w h}$ in existing energy plants and systems is an important task.

Presently, there is a number of new technologies for energy utilization, among them the one based on thermoacoustic effect [1]. Thermoacoustics combines the fields of thermodynamics and acoustics and describes the process of interaction between heat and sound energy. The work of thermoacoustic devices (TAD) is based on the mutual transformation of heat and acoustic energies. The main feature of thermoacoustic systems is that unlike the other heat machines, the powerful acoustic pulses [2], generated by TAD are the carriers of mechanical energy and the "executive mechanism" of thermodynamic cycle.

Considering the thermoacoustic processes (TAP) reversibility, thermoacoustic devices can be divided into two main types [3-5]:

- thermoacoustic engines (TAE) that consume supplied heat energy and produce acoustic wave inside the resonator;

- thermoacoustic refrigerators (TAR) and heat pumps (TAHP) that consume energy from supplied 
acoustic wave and produce cooling or heating power, respectively.

The design of WHE utilization plants based on the thermoacoustic effect includes two main parts. First is the TAE that converts supplied waste heat into acoustic energy inside the TAD resonator. The second part is the TAHP, which uses the acoustic energy and thermoacoustic effect to heat up the supplied WHE or another supplied coolant. Thus, the output temperature of TAHP could be over 100 degrees higher than the temperature of supplied coolant.

The efficiency of thermoacoustic devices highly depends on the optimal values of its internal parameters (viscosity, density, thermal conductivity) and the environment effects (temperature, pressure, etc.).

An effective work of TAD is possible only if the different nature values of the internal parameters (acoustic, hydrodynamic, thermal) are stabilized. Optimization of thermodynamic cycle, improvement of the hydrodynamic and heat transfer processes can increase the efficiency of thermoacoustic devices. Therefore, it is reasonable and necessary to develop the automatic system for thermoacoustic processes control.

\section{DESCRIPTION OF EXPERIMENTAL PLANT FOR TAD ANALYSIS}

The main published results in the field of automated monitoring and analysis of TAP are based on the electro-acoustic systems, which use the loudspeaker as the source of acoustic pulses inside the TAD resonator. In particular, in [5] the structure and algorithms of computer system are considered for loudspeaker driven thermoacoustic refrigerator energy and acoustic parameters analysis [1]. Methods of assessing the acoustic power in these systems are based on the measurement of pressure $p(t)$ using the pressure sensors and evaluation of the oscillatory velocity $v(t)$ in the resonator by measuring the acceleration $a(t)$ of loudspeaker membrane using the accelerometer. This narrows the scope of use for such computerized systems only by the automation of electroacoustic installations.

The direct method [1] that combines the simultaneous measurements of $p(t)$ (by the pressure transducer) and $v(t)$ (by the laser Doppler velocity meter) is usually used for determination of the sound waves parameters in thermoacoustic systems. This approach allows determining the value of the acoustic pressure $p(t)$ and the oscillatory velocity $v(t)$ with high accuracy, but requires expensive equipment and the availability of transparent zone in resonator to undergo laser beams. These shortcomings limit the possibility of the direct method usage only by research systems, and make its implementation in TAD automated control systems unreasonable.

Proposed by the authors, computerized system for monitoring and control of thermoacoustic processes implements the two sensors method [6] for acoustic wave's parameters estimation in the resonator of thermoacoustic device. This approach allows the avoidance of the drawbacks and limitations of the above stated methodologies and makes possible the creation of the universal system for thermoacoustic processes automated monitoring.

Fig. 1 shows the structure and main components of the computerized system [7] for the thermoacoustic processes parameters determination. Due to the thermoacoustic process features, the computer system must combine rapid data (acoustic pressure actuations, current and voltage oscillations) and slow data signals (temperature variations). Thus, it is necessary to use the distributed structure for the created monitoring system (Fig. 1).

The main elements of the system are: personal computer (PC), pressure $(P S 1, \ldots, P S 4)$, temperature $(T S 1, \ldots, T S 4)$, current $(C S)$ and voltage (VS) sensors; programmable logic controller (PLC) ICPDAS $\mu \mathrm{PAC}$ 7186EX-SM that collects the thermal behavior data of TAD; microcontroller (MCU) STM32F407VGT6, that is used to collect rapidly changing data from the system pressure, current and voltage sensors and transfer it to the PC.

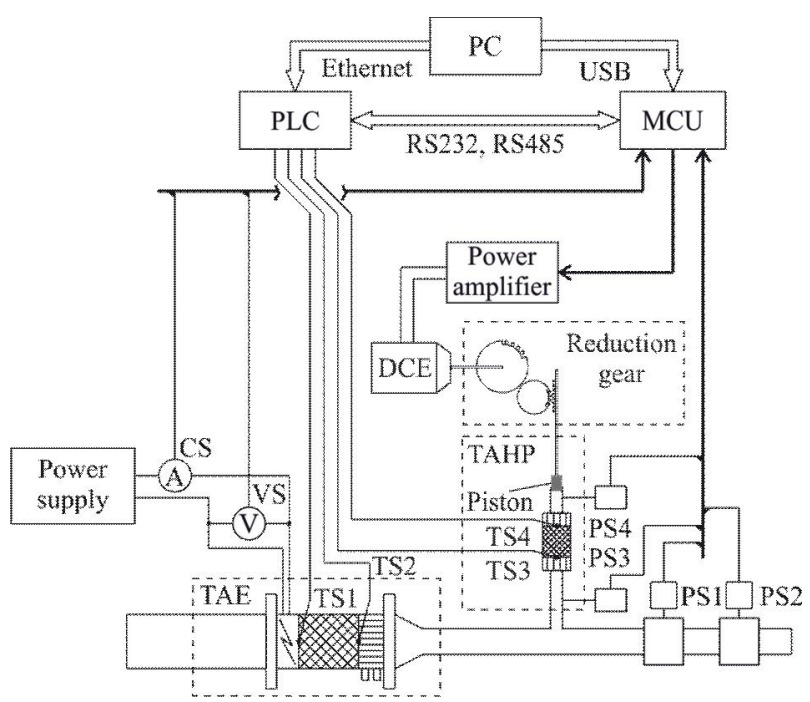

Fig. 1 - The computerized system for control of thermoacoustic devices

STM32F4 microcontroller has three analog-todigital converters, which are characterized by 12-bit resolution and conversion frequency of up to 2.4 Msps. This provides high performance and applicability of the proposed computer system for any thermoacoustic unit, since the operating frequency range of TAD does not exceed tens of kHz. PLC performs data acquisition of the current 
status of TAD peripheral equipment and sends it to $\mathrm{PC}$ through the Ethernet networks.

The designed system allows the communication between all components via RS232 network, also to enable the transfer of large amounts of data, PLC supports the Ethernet connection with $\mathrm{PC}$ and $\mathrm{MCU}$ can communicate with PC via USB. This grants maximum flexibility to designed distributed computer system.

Created software for PC allows storing the received from the controller information in the archive database; execution of the necessary algorithms for digital processing of measured signals, and displaying all available information on the user's screen.
Therefore, the proposed structure of distributed computer system allows the registration and ongoing monitoring of the thermoacoustic processes.

\section{EXPERIMENTAL STUDIES OF THERMOACOUSTIC ENGINE}

The tests of proposed by the authors computerized system were conducted using the experimental thermoacoustic engine (Fig. 2) [1,7], with a resonator length of $1010 \mathrm{~mm}$ and diameter of $46 \mathrm{~mm}$, which was filled with air at atmospheric pressure. Engine was coupled with thermoacoustic heat pump (TAHP), which acted as a payload of the system (Fig. 1).

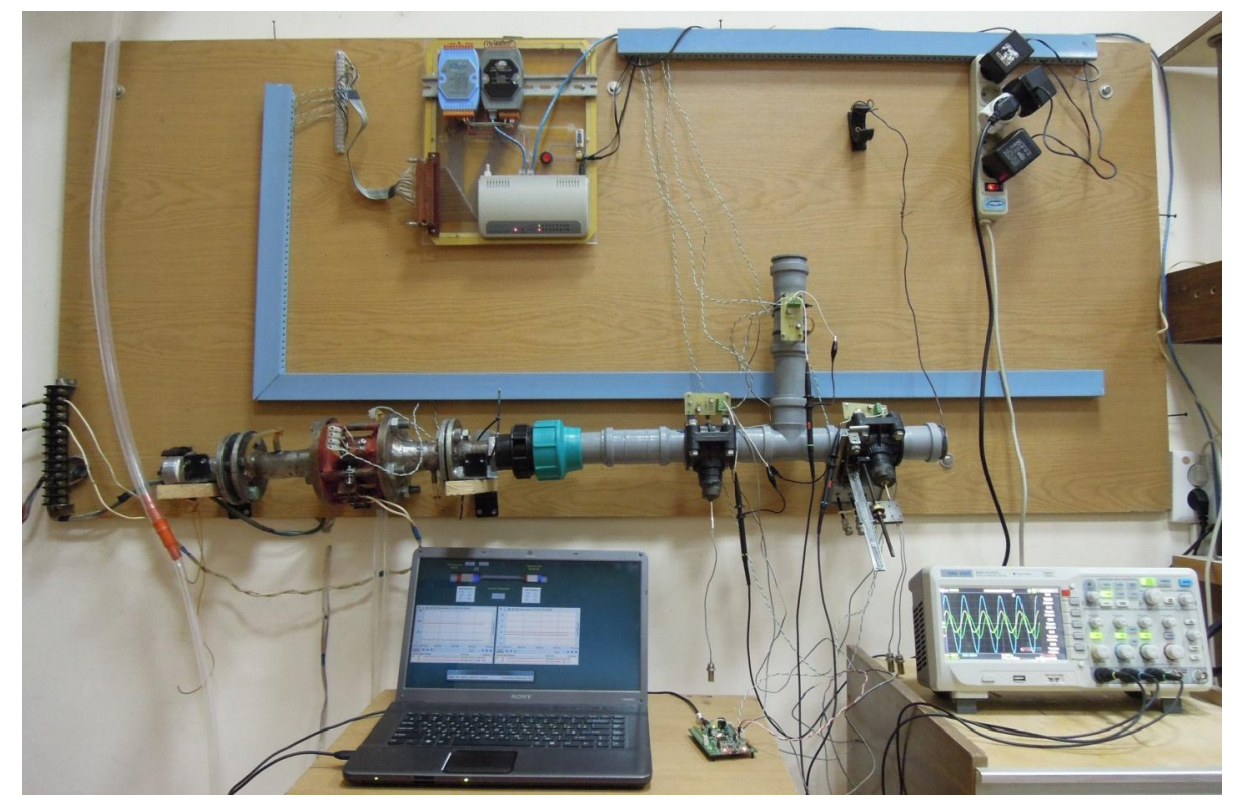

Fig. 2 - Photo of the experimental plant for TAD analysis

TAE convert's supplied heat $P_{Q}$ into acoustic power $P_{a c}$, so its efficiency can be estimated as the ratio of established acoustic power to the supplied heat. In the experimental plant (Fig. 1) the nichrome heater is used as a source of the thermal energy $P_{Q}$ and thus supplied power $P_{\text {supl }}$ can be calculated through the consumption of electricity $P_{e l}$ by the heater (2), supplied by the power supply unit and measured by the current sensor ACS712ELCTR05B-T, and the voltage divider.

$$
\eta_{T A E}=\frac{P_{a c}}{P_{\text {sup } l}} \cdot 100 \%=\frac{P_{a c}}{P_{e l}} \cdot 100 \%,
$$

To calculate the acoustic power $P_{a c}$, the information from two pressure sensors MPXV7007DP (PS1 and PS2 in Fig. 1), which are situated at a $\Delta x=160 \mathrm{~mm}$ distance from each other, is collected by the MCU. Based on the data obtained from PS1 and PS2 the acoustic power can be calculated using the two sensor method [6]. This method allows the calculation of pressure $p_{0}(t)$, particle velocity $v_{0}(t)$ and acoustic power $P_{a c}(t)$ at the point that is situated in the middle $(\Delta \mathrm{x} / 2)$ between the points of pressure measurements. It should be noted that calculated by the described method values of particle velocity $v_{0}(t)$ and acoustic power $P_{a c}$ were verified by the data obtained directly from the hotwire anemometer.

Distance from the engine edge to the first pressure sensor is $745 \mathrm{~mm}$, and to the second -905 $\mathrm{mm}$. Control of thermal data of the system was carried out using the thermocouples TS (Fig. 1).

Fig. 3 shows the results of TAE experimental measurements. Fig. 3, a illustrates the parameters of acoustic waves that were calculated using two sensors method. Thermoacoustic engine starting process is shown in Fig. 3, b, where on the top there are rooted mean square values (3) of calculated pressure $p_{0}(t)$ and particle velocity $v_{0}(t)$ and on the 
bottom - temperature changes in points TS1 and TS2 (Fig. 1).

$$
R M S(x)=\sqrt{\frac{1}{N} \sum_{k=1}^{N} x_{k}^{2}},
$$

where $x_{k}$ - experimental data sample, $N=10000$ samples - RMS period.

Calculated TAE efficiency values along with other experimental results are shown in Table 1 . The experimental series include five tryouts with different supplied power. It should be noted that these values of efficiency are typical for air filled $\mathrm{TAD}$ working under atmospheric pressure.

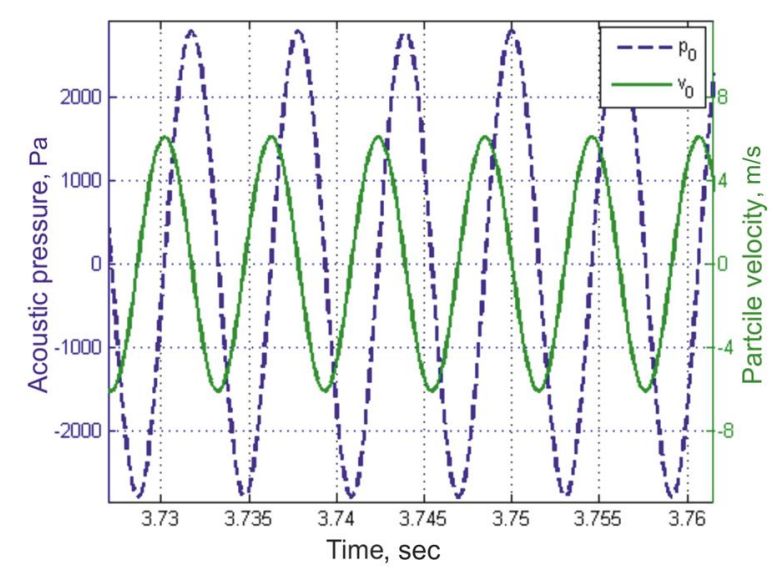

a) instant values of pressure $p_{0}(t)$ and velocity $v_{0}(t)$
Table 1. Results of the experimental study of TAD acoustic energy parameters

\begin{tabular}{|c|c|c|c|c|c|}
\hline \multirow{2}{*}{ Parameter } & \multicolumn{5}{|c|}{ Experiment number } \\
\cline { 2 - 6 } & $\mathbf{1}$ & $\mathbf{2}$ & $\mathbf{3}$ & $\mathbf{4}$ & $\mathbf{5}$ \\
\hline $\mathrm{T}_{\mathrm{H}}, \mathrm{K}$ & 548.6 & 568.5 & 632.5 & 594.9 & 648.6 \\
\hline $\mathrm{T}_{\mathrm{C}}, \mathrm{K}$ & 287.8 & 303.8 & 320.1 & 322.5 & 349 \\
\hline $\mathrm{I}, \mathrm{A}$ & 2.3 & 3 & 3.5 & 4 & 5 \\
\hline $\mathrm{U}, \mathrm{V}$ & 23.1 & 31.1 & 37 & 41.5 & 51.8 \\
\hline $\mathrm{P}_{\mathrm{el}}, \mathrm{W}$ & 53.13 & 93.3 & 129.5 & 166 & 259 \\
\hline $\mathrm{p}_{0}, \mathrm{~Pa}$ & 543 & 1768 & 2021 & 2795 & 4128 \\
\hline $\mathrm{v}_{0}, \mathrm{~m} / \mathrm{s}$ & 0.85 & 3.2 & 3.8 & 5.93 & 7.27 \\
\hline $\mathrm{P}_{\mathrm{ak}}, \mathrm{W}$ & 0.39 & 4.8 & 6.4 & 14.16 & 22.4 \\
\hline$\eta_{\mathrm{TAE}}, \%$ & 0.73 & 5.14 & 5 & 8.53 & 8.56 \\
\hline
\end{tabular}
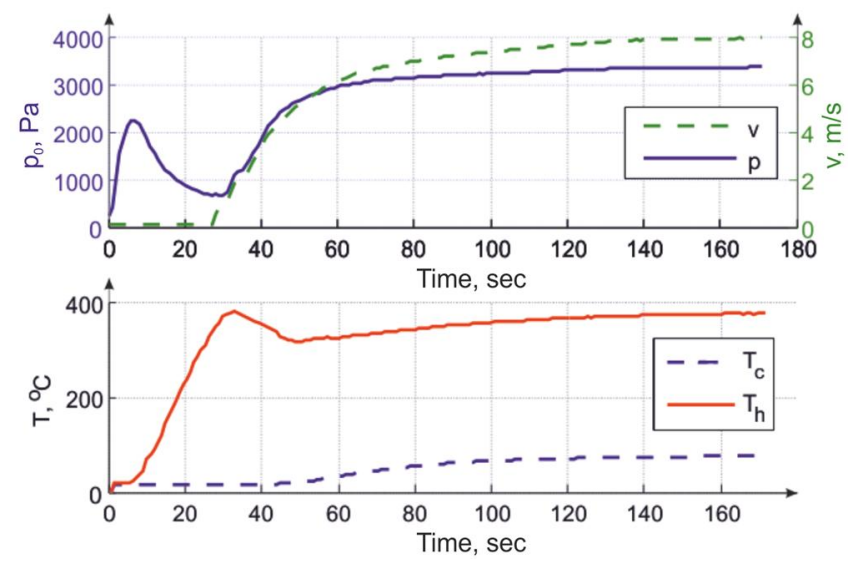

b) TAE starting process

Fig. 3 - Results of the experimental study of TAE working process

Enhancements of TAE efficiency can be achieved by the structural changes in the engine, increase of the operating pressure in the resonator and by replacement of the TAE working fluid from air to helium.

Further research showed that in given configuration the maximum pressure magnitude inside the TAE resonator depends on the length of TAHP resonator branch [7]. Thus, the control of TAD working process can be made by the adjustments in TAHP resonator length. Therefore, further let's consider the synthesis of TAD control system based on the change of the TAHP resonator length.

\section{SYNTHESIS OF THE THERMOACOUSTIC PROCESSES CONTROL SYSTEM}

Based on the results of experimental studies (Fig. 3), it can be concluded that the TAE can be described by the first order transfer functions that represent the pressure $p(t)$ and particle velocity $v(t)$ which are generated due to the supplied power $P_{\text {supl }}(t)$. The exact values of pressure (4) and velocity (5) transfer functions (TF) were identified using the least squares regression method [8] with the desired functionality in the form (6).

$$
\begin{aligned}
& W_{p}(p)=\frac{14.66}{48.72 \mathrm{p}+1}, \\
& W_{U}(p)=\frac{5 \cdot 10^{-5}}{41.36 \mathrm{p}+1},
\end{aligned}
$$

It should be noted that TF $W_{U}(p)$ (5) represents volume velocity in TAE resonator and it can be calculated as $U(t)=v(t) A$ with $A$ is the cross section area of TAE resonator.

$$
\min _{k, T} J(k, T)=\min _{k, T} \sum_{j=1}^{N}\left[\frac{k}{T} e^{\frac{-t}{T}}-y_{j}\right]^{2},
$$

where $k, T$ - parameters of first order link, $y-$ experimental sample, $N$ - experimental sample length.

TAHP branch is represented by the transfer matrix $W_{T A H P}(p)$ that is based on the Rott's 
representation of continuity (7) and momentum (8) equations [1] and identified model (9) of temperature difference $W_{T}(p)$ between the stack hot TS4 and cold TS3 ends (Fig. 1). For the given geometry of experimental thermoacoustic plant equations (7) and (8) can be represented by a matrix (10).

The change of the TAHP resonator length is simulated by the system that transforms direct current (DC) engine $W_{D C E}(p)$ rotational movement into linear using the reduction gear. The effect of resonator length change is simulated by the experimentally obtained nonlinear dependency of pressure magnitude $p(t)$ from the acoustic wave frequency inside the TAHP resonator.

The relation between TAHP resonator length $L_{\text {res }}$ and acoustic wave frequency $f_{\text {res }}$ are caharacterized by equation (11).

$$
\begin{gathered}
\frac{d p}{d x}=-\frac{1}{A} \frac{i \omega \rho_{m}}{1-f_{v}} u_{1}, \\
\frac{d u_{1}}{d x}=-A \frac{i \omega\left[1+(\gamma-1) f_{k}\right]}{\gamma p_{m}} p+\frac{f_{k}-f_{v}}{\left(1-f_{v}\right)(1-\sigma)} \frac{1}{T_{m}} \frac{d T_{m}}{d x} u_{1}, \\
W_{T}(p)=\frac{7,18 \cdot 10^{-4} p+6,05 \cdot 10^{-6}}{p^{2}+0,12 p+5,49 \cdot 10^{-4}}, \\
W_{\text {TATH }}(p)=\left[\begin{array}{cc}
0.903+0.002 i & 1.006 \cdot 10^{3}+9.094 \cdot 10^{4} i \\
-9.715 \cdot 10^{-9}-2.024 \cdot 10^{-6} i & 0.903+0.002 i
\end{array}\right],
\end{gathered}
$$

where $\rho_{\mathrm{m}}$ - density of the medium; $\sigma$ - Prandtl number; $\mathrm{T}_{\mathrm{m}}$ - function of the temperature field distribution along the resonator; $p$ - acoustic pressure; $\mathrm{u}_{1}-$ volume velocity; $f_{v}$ та $f_{k}$ - Rott functions that depend on the geometry and thermal properties of the stack and gas mixture; $\gamma$ - universal gas constant, for air $\gamma=1.4 ; \mathrm{A}$ - cross sectional area of resonator; i - imaginary unit; $\omega$ - acoustic wave frequency.

$$
f_{\text {res }}=\frac{a}{\lambda}=\frac{\sqrt{\gamma k T / m}}{n L},
$$

where $f$ - sound wave frequency; $a$ - speed of sound; $\lambda$ - sound wave length; $k$ - Boltzmann constant; $\gamma$ - the adiabatic coefficient of gases; $T-$ absolute temperature; $m$ - molecular mass of gas; $L$ - resonator length; $n$ - acoustic wave length multiplier.

The resulting linear [9] model of TAD is shown in Fig. 4. The input values for the system are: supplied to TAE electric power $P_{\text {supl }}$, starting length of TAHP resonator $L_{T A H P}$, value of cold end of TAHP stack $T_{C}$, value of speed of sound $a=343 \mathrm{~m} / \mathrm{s}$ and desired temperature $T_{\text {des }}$ of TAHP stack hot end.

The acoustic wave length multiplier $n$, for current setup is equal to 2 (half wave length resonator), $k_{R}$ is the reduction gear coefficient that transforms rotational movement of the DC engine into the TAHP resonator end piston translational movement.
The acoustic pressure magnitude is adjusted by the value of the nonlinear dependency $p_{m}\left(f_{\text {res }}\right)$,, which is normalized by the pressure value at the resonant frequency (11). The output of the system is the value of the TAHP stack hot end $T_{H}(p)$.

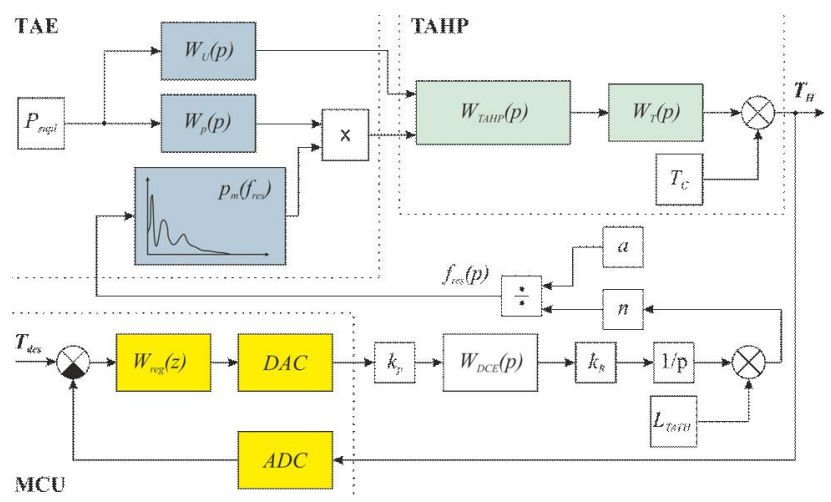

Fig. 4 - The resulting model of the system for TAD control by the TAHP resonator length adjustment

The simulation of synthesized TAD model working process is shown in Fig. 5.

It demonstrates that the implementation of control system decreases the transient response time (with 5\% setting bounds) from $t_{\text {trans }}^{T A D}=365.6 \mathrm{sec}$ to $t_{\text {trans }}^{P D}=301.3 \mathrm{sec}$.

The desired value of TAHP stack hot end is set to $T_{\text {des }}=45^{\circ} \mathrm{C}$. Synthesized system uses the discrete [10] proportional-derivative (PD) regulator, whose transfer function is defined in the equation (10). 


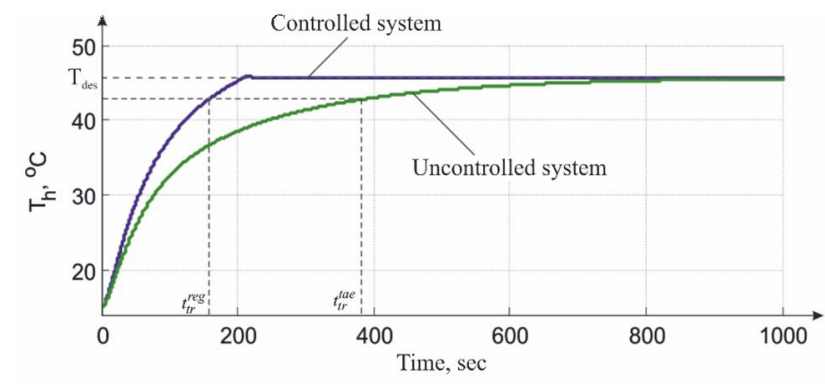

Fig. 5 - Simulation results of synthesized TAD model

$$
\left.W_{\text {reg }}(z)\right|_{T_{0}=0.1}=\frac{6.037 z-5.374}{z-0.06542} .
$$

It should be noted that the discretization period of $\mathrm{T}_{0}=0.1 \mathrm{sec}$ is equal to the sample time of thermocouple data acquisition module.

\section{SYNTHESIS OF FUZZY CONTROLLERS FOR THE TAE DRIVEN PLANT}

Fuzzy control provides a formal methodology [11] for representing, manipulating, and implementing a human's heuristic knowledge about how to control a system.

Fuzzy controllers are applicable primarily to manage objects that either could not be described or could be described with great difficulties. However, even for control objects, for which mathematical model could be obtained, these regulators are often better than others, because they allow to obtain higher quality (fewer errors in transient and steady state) of automatic control.

The microcontroller based fuzzy controller [12] block diagram for thermoacoustic plant is given in Fig. 6, where the fuzzy controller embedded in a closed-loop control system is shown.

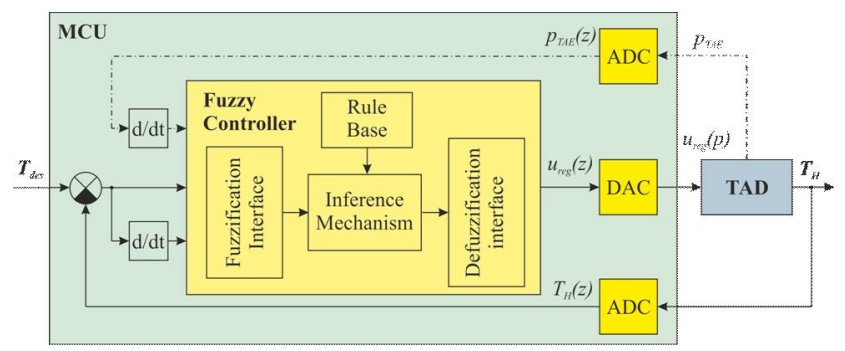

Fig. 6 - Block diagram of the TAD control system with MCU-based fuzzy controller

Authors designed [13] PD fuzzy controllers of Mamdani and Sugeno types for the control system of thermoacoustic plant. The input signals for controllers are the error signal between the desired and current temperature of hot end of TAHP stack $\left(\varepsilon=\mathrm{T}_{\text {des }}-\mathrm{T}_{\mathrm{H}}\right)$ and the first derivative of the error signal. Input signals of fuzzy controllers are described by five triangular terms, and the output signal $\mathrm{u}_{\mathrm{reg}}$ is described by the seven terms for Mamdani controller (Table 2) and first order polynomial for Sugeno controller. The knowledge base of fuzzy system consists of 25 rules (Table 3 ).

Table 2. Terms of Mamdani fuzzy controller

\begin{tabular}{|c|c|c|}
\hline Term & $\begin{array}{l}\text { Membership } \\
\text { function }\end{array}$ & $\begin{array}{c}\text { Range of } \\
\text { values }\end{array}$ \\
\hline \multicolumn{3}{|c|}{ For input variable $\varepsilon$} \\
\hline BN - Big Negative & Triangle & {$\left[\begin{array}{lll}-1.5 & -1 & -0.5\end{array}\right]$} \\
\hline SN - Small Negative & Triangle & {$\left[\begin{array}{lll}-1 & -0.5 & 0\end{array}\right]$} \\
\hline Z-Zero & Triangle & {$\left[\begin{array}{lll}-0.5 & 0 & 0.5\end{array}\right]$} \\
\hline SP - Small Positive & Triangle & {$\left[\begin{array}{lll}0 & 0.5 & 1\end{array}\right]$} \\
\hline BP - Big Positive & Triangle & {$\left[\begin{array}{llll}0.5 & 1 & 1.5\end{array}\right]$} \\
\hline \multicolumn{3}{|c|}{ For input variable $d \varepsilon / d t$} \\
\hline BN - Big Negative & Triangle & {$\left[\begin{array}{lll}-1.5 & -1 & -0.5\end{array}\right]$} \\
\hline SN - Small Negative & Triangle & {$\left[\begin{array}{lll}-1 & -0.5 & 0\end{array}\right]$} \\
\hline Z-Zero & Triangle & {$\left[\begin{array}{lll}-0.5 & 0 & 0.5\end{array}\right]$} \\
\hline SP - Small Positive & Triangle & {$\left[\begin{array}{lll}0 & 0.5 & 1\end{array}\right]$} \\
\hline BP - Big Positive & Triangle & $\left.\begin{array}{llll}0.5 & 0.5 & 1 & 1.5\end{array}\right]$ \\
\hline \multicolumn{3}{|c|}{ For output variable $u_{r e g}$} \\
\hline BN - Big Negative & Triangle & {$\left[\begin{array}{lll}-1.5 & -1 & -0.67]\end{array}\right]$} \\
\hline $\begin{array}{lll}\text { MN }- & \text { Middle } \\
\text { Negative } & \\
\end{array}$ & Triangle & $\begin{array}{c}{[-1-0.67-} \\
0.33]\end{array}$ \\
\hline SN - Small Negative & Triangle & {$\left[\begin{array}{lll}-0.67 & -0.330 \\
0\end{array}\right.$} \\
\hline$Z$-Zero & Triangle & {$\left[\begin{array}{lll}-0.33 & 0 & 0.33\end{array}\right]$} \\
\hline SP - Small Positive & Triangle & {$\left[\begin{array}{llll}0 & 0.33 & 0.67\end{array}\right]$} \\
\hline $\begin{array}{l}\text { MP - } \\
\text { Positive }\end{array}$ & Triangle & {$\left[\begin{array}{llll}0.33 & 0.67 & 1\end{array}\right]$} \\
\hline BP - Big Positive & Triangle & {$\left[\begin{array}{llll}0.67 & 1 & 1.5\end{array}\right]$} \\
\hline
\end{tabular}

Table 3. Knowledge base of Mamdany fuzzy controller

\begin{tabular}{|c|c|c|c|c|c|c|}
\hline & \multicolumn{5}{|c|}{ Error derivative, $d \varepsilon / d t$} \\
\hline & & $\mathrm{BN}$ & SN & $\mathrm{Z}$ & SP & BP \\
\hline \multirow{5}{*}{$\begin{array}{c}\text { Error, } \\
\quad \varepsilon\end{array}$} & $\mathrm{BN}$ & $\mathrm{BN}$ & $\mathrm{BN}$ & $\mathrm{BN}$ & MN & SN \\
\hline & SN & $\mathrm{BN}$ & MN & $\mathrm{MN}$ & SN & SP \\
\hline & $\mathrm{Z}$ & SN & SN & $\mathrm{Z}$ & SP & SP \\
\hline & SP & SN & SP & MP & MP & BP \\
\hline & BP & SP & MP & BP & BP & BP \\
\hline
\end{tabular}

Transient responses comparison of created Mamdani and Sugeno fuzzy controllers with two input variables is given in Fig. 7. Based on the analysis of results obtained (Fig. 7) it could be concluded that the Sugeno fuzzy controller enhances the control system with best quality indicators of transient response, including the response time of $149.39 \mathrm{sec}$ and static error of $0.06^{\circ} \mathrm{C}$.

Application of fuzzy logic paradigms $[13,14]$ for design of controllers for WHE utilization system driven by the TAE allows to create the hybrid controller that responds not only to changes in the values of the hot heat exchanger of TAHP branch $\left(\mathrm{T}_{\mathrm{H}}\right)$, but also to the value of the pressure derivative $\left(\mathrm{p}_{\mathrm{TAE}}\right)$ inside the TAE. Additional feedback is shown in Fig. 6 by the dash-dot line. Synthesized according to this principle hybrid Sugeno fuzzy controller has three input signals, each of which is described by 
five triangular terms and their relations are characterized by the knowledge base, consisting of 125 rules. Seven first order polynomials form the output signal of the controller.

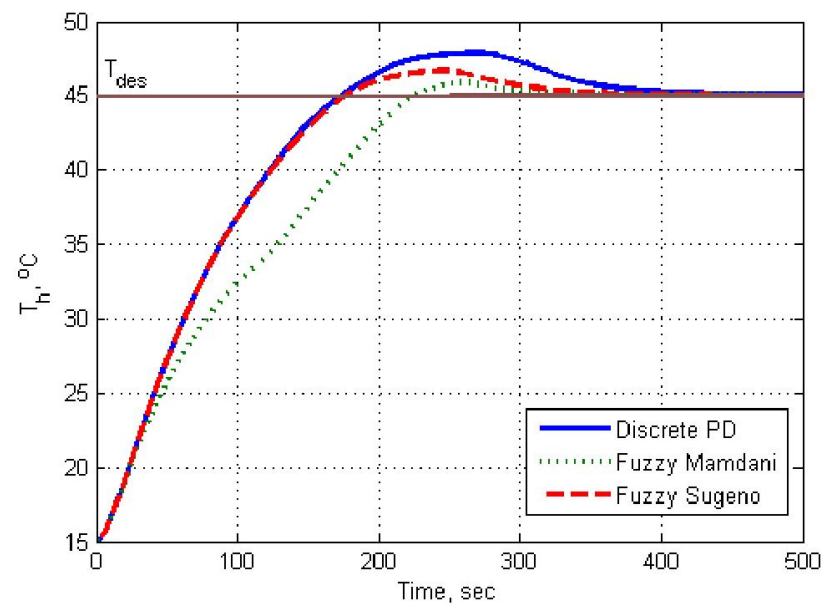

Fig. 7 - Comparison of designed fuzzy and discrete PD controllers

Input membership functions of the hybrid fuzzy controller are given in Fig. 8 and its characteristic surfaces are shown in Fig. 9. A comparative analysis of the quality indicators of the TAD control system transient response (Fig. 10) with PD and hybrid Sugeno fuzzy controllers are shown in Table 4.
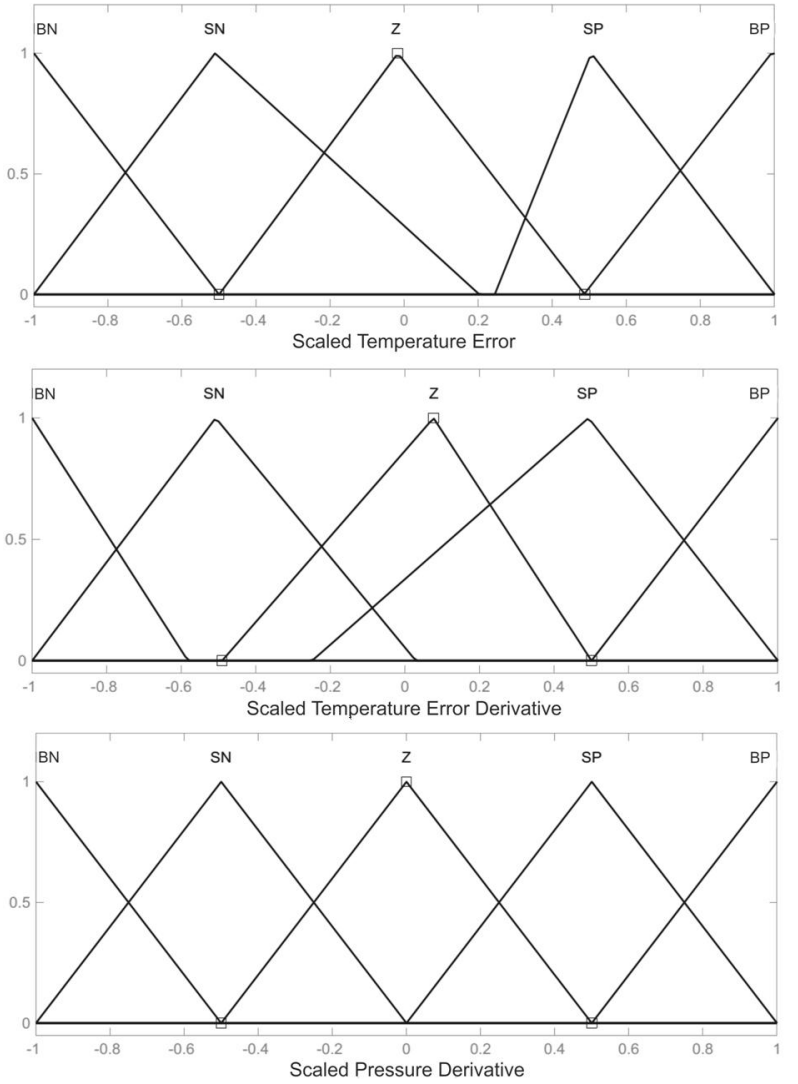

Fig. 8 - Input membership functions of the synthesized hybrid fuzzy controller
Designed hybrid fuzzy controller provides better dynamical characteristics of the WHE utilization system driven by the thermoacoustic engine. It should be noted that with the introduction of an additional variable to the regulating law it is possible to increase the robust properties of the synthesized control system.

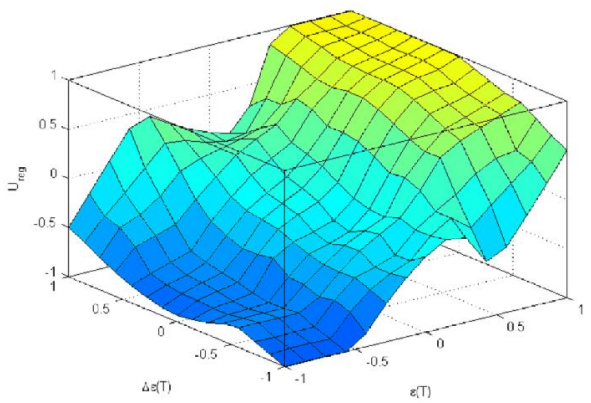

a) $\mathbf{u}_{\mathrm{reg}}=f(d \varepsilon, \varepsilon)$

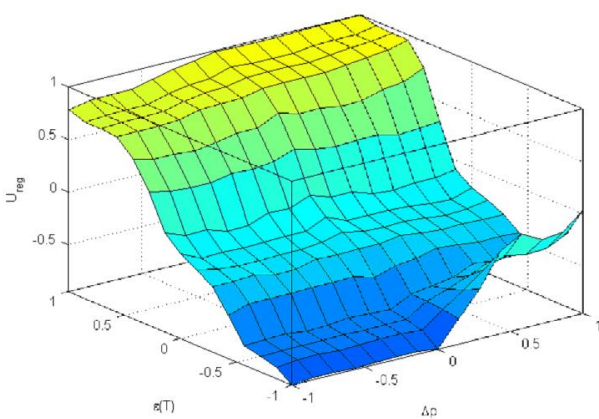

b) $\mathrm{u}_{\mathrm{reg}}=f(\varepsilon, d p)$

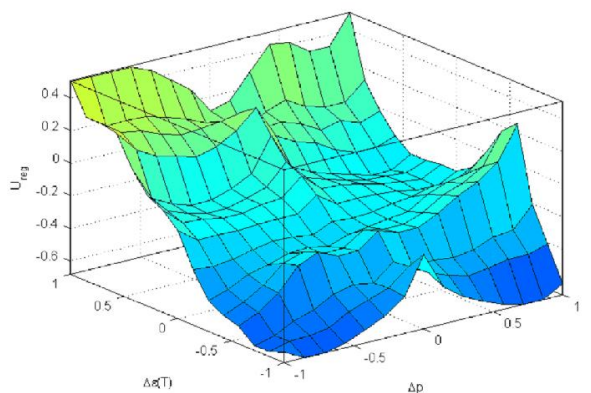

c) $\mathbf{u}_{\mathrm{reg}}=f(d \varepsilon, d p)$

Fig. 9 - Characteristic surfaces of the synthesized hybrid fuzzy controller

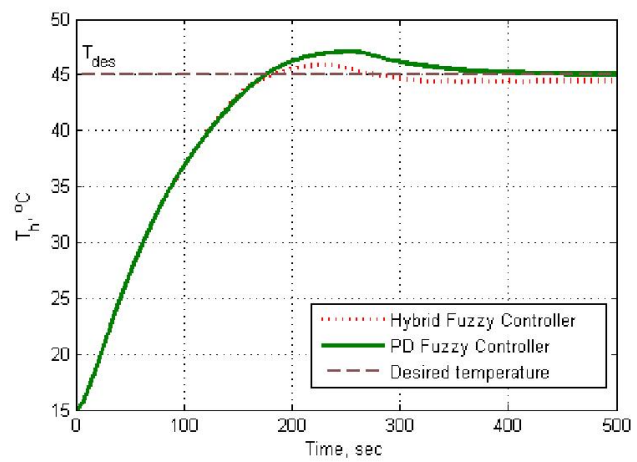

Fig. 10 - Comparison of designed PD and hybrid Sugeno fuzzy controllers 
Table 4. Results of the experimental study of TAD acoustic energy parameters

\begin{tabular}{|c|c|c|c|c|}
\hline Parameter & $\begin{array}{c}\text { Discrete } \\
\text { PD }\end{array}$ & $\begin{array}{c}\text { Fuzzy } \\
\text { Mamdani }\end{array}$ & $\begin{array}{c}\text { Fuzzy } \\
\text { Sugeno }\end{array}$ & $\begin{array}{c}\text { Hybrid } \\
\text { Sugeno }\end{array}$ \\
\hline $\begin{array}{c}\text { Transient } \\
\text { response time, sec }\end{array}$ & 301.3 & 197.65 & 149.39 & 146.77 \\
\hline Overshot, $\%$ & $6.34 \%$ & $1.97 \%$ & $3.77 \%$ & $1.97 \%$ \\
\hline Static error, ${ }^{\circ} \mathrm{C}$ & 0.06 & 0.03 & 0.06 & 0,56 \\
\hline
\end{tabular}

\section{CONCLUSION}

The article presents the design of optimum controller for waste heat utilization plant with thermoacoustic engine. Authors describe the series of regulators that by changing the length of the heat pump branch resonator can stabilize the output temperature of the thermoacoustic system. A comparative analysis of continuous PD controller with the fuzzy controllers of Mamdani and Sugeno types showed the feasibility of control devices on fuzzy logic for control of thermoacoustic devices.

The authors propose a hybrid fuzzy logic controller which also reacts to changes in the acoustic pressure of the thermoacoustic engine. Such controller grants to the control system best dynamic qualities in comparison to other regulators (Table 4).

\section{REFERENCES}

[1] G. W. Swift, Thermoacoustics - A Unifying Perspective for Some Engines and Refrigerators, Acoustical Society of America, 2002, $300 \mathrm{p}$.

[2] Lord Rayleigh, The theory of sound, $2^{\text {nd }}$ edition, Vol. 2., Dover, NewYork, 1945.

[3] J. C. Wheatley, G. W. Swift, A. Migliori, The natural heat engines, Los Alamos Science, (14) 2 (1986), pp. 2-33.

[4] S. M. Mehta, K. P. Desai, H. B. Naik, M. D. Atrey, Design of standing wave type thermoacoustic prime mover for $300 \mathrm{~Hz}$ operating frequency, Proceedings of the $16^{\text {th }}$ International Crycooler Conference, USA (2011), pp. 343-352.

[5] T. S. Ryan, Design and control of a standingwave thermoacoustic refrigerator, University of Pittsburgh, 2006, $101 \mathrm{p}$.

[6] A. M. Fusco, W. C. Ward, G. W. Swift, Twosensor power measurements in lossy ducts, Journal of Acoustic Society of America, (91) (1992), pp. 2229-2235.

[7] Y. Kondratenko, V. Korobko, O. Korobko, Distributed Computer System for Monitoring and Control of Thermoacoustic Processes,
Proceedings of the $7^{\text {th }}$ IEEE International Conference IDAACS'2013, Berlin, Germany (12-14 September, 2013), pp. 249-253.

[8] J. Wolberg, Data Analysis Using the Method of Least Squares: Extracting the Most Information from Experiments, Springer, 2005.

[9] A. V. Sholokhov, Development of the guaranteed estimation robust algorithm of linear controlled system states, International Journal of Computing, (10) 3 (2011), pp. 235-248.

[10] O. Maler, A. Pnueli, J. Sifakis, On the synthesis of discrete controllers for timed systems, in: E. W. Mayr, C. Puech (eds.), Lecture Notes in Computer Science, (900) (1995), pp. 229-242.

[11] L. Zadeh, J. Kacprzyk, Fuzzy Logic for the Management of Uncertainty, John Wiley \& Sons, New York, 1992, $676 \mathrm{p}$.

[12] W. Banks, G. Hayward, Fuzzy Logic in Embedded Microcomputers and Control Systems, Byte Craft Limited, North Waterloo, Ontario Canada, 2002, 75 p.

[13] R. R. Yager, D. P. Filev, Essentials of Fuzzy Modeling and Control, John Wiley \& Sons, 1994, $388 \mathrm{p}$.

[14] P. Bykovyy, Y. Pigovsky, A. Sachenko, A. Banasik, Fuzzy Inference System for Vulnerability Risk Estimation of Perimeter Security, Proceedings of IEEE International Workshop on Intelligent Data Acquisition and Advanced Computing Systems, Rende, Italy, (21-23 September, 2009), pp. 380-384.

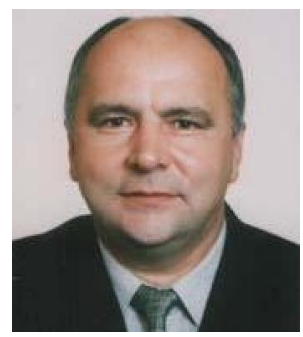

Yuriy Kondratenko, DSC, Professor, professor of Intelligent Information Systems Department of Petro Mohyla Black Sea State University. Scientific interests: Intelligent decision support systems, information technologies, automatic control,

computer systems and components, fuzzy logic.

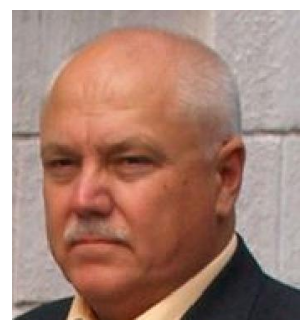

Volodymyr Korobko, PhD, Associated professor of Marine and Stationary Power Plants Department of Admiral Makarov National University of Shipbuilding. Scientific interests: thermophysics, marine engineering, marine power plants,

recycling waste energy, renewable energy, thermoacoustic. 


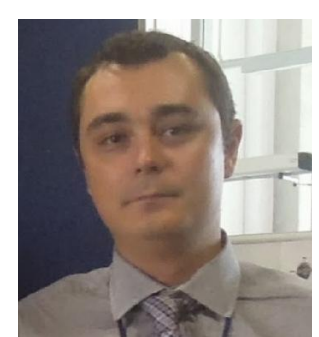

Oleksiy Korobko, PhD, senior

lecturer of Computer-aided Control Systems Department of Admiral Makarov National University of Shipbuilding. Scientific interests: distributed control systems, embedded systems, automation of tech-

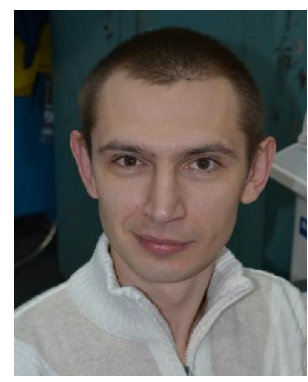

Oleksiy Moskovko, PhD student of Marine and Stationary Power Plants Department of Admiral Makarov National University of Ship-building. Scientific interests: marine engineering, $\quad C A D / C A M / C A E$, marine power plants, thermoacoustic, CFD modeling. 